\title{
Ecological aspects of the traditional brick making process in pedurungan kidul, central java
}

\author{
Paramita Atmodiwirjo ${ }^{1, *}$, Mikhael Johanes ${ }^{1}$, Diandra Pandu Saginatari ${ }^{1}$, and Yandi Andri Yatmo ${ }^{1}$ \\ ${ }^{1}$ Department of Architecture, Faculty of Engineering, Universitas Indonesia, Depok, Indonesia
}

\begin{abstract}
Traditional building materials play an important role in the construction of sustainable built environment. Clay bricks as traditional materials have been made with traditional techniques handed down across generation in many countries. The traditional process has become an integral part of the social and cultural life of the local society which forms the ecological relations between architecture and its context. The presence of the traditional process of brick making is currently challenged by the more modern industrial brick production. Some concerns have been raised regarding various environmental and health hazards from the brick making process. On the other hand, as a production process that has been handed down across generation, the brick making process is embedded with various ecological values that are attached to the environmental and cultural context where the production is performed and where the material resources are originated. This paper attempts to review ecological aspects that are involved in the traditional brick making production. In particular, this paper presents a preliminary analysis to identify the ecological aspects in brick making process in Pedurungan Kidul, Central Java, Indonesia. The findings suggest the need to consider the traditional brick making process as a comprehensive ecological system and therefore several research agendas are proposed for further investigation.
\end{abstract}

\section{Introduction}

The ecological approach in architecture is strongly attached to the building materials used in the construction. In many cultures, the traditional brick making still becomes the preferred form of material practice. As a setting for production process, traditional brick making workshop is attached to the environmental and cultural contexts where the process is performed and where the material resources are originated. Being attached to the environmental context implies the inclusion of the ecological values from environmental context in the whole making process. The traditional brick making workshop has always been a part of cultural, urban, and natural landscape that collide with the ecological system that constructs the area. The traditional brick making process generally consists of the stages of mixing, molding, drying, and frying [1] that begin with the excavation process of the raw material of clay and other mixing ingredients such as sand or ashes. Within each process, there are actions of taking something from the environment, the raw materials, and giving something to the environment, the production of waste. These actions interweave with the ecological system in the environmental context and have impact to the environment in general.

As a cultural practice, traditional brick making process is embedded with indigenous knowledge which contributed to the ecological value of architectural practice within its particular context. Indigenous knowledge becomes a medium to understand the formation process of the design, configuration and elements of architecture and built environment [2]. As a knowledge that intimately relates to the livelihood of the people [3], indigenous knowledge is practiced in the traditional brick making process as part of the daily life of the people. The workers perform this particular practice of brick making process based on the technique that have been handed down through generation and based on the potentials and resources offered by that particular environment. This technique could be considered as traditional ecological knowledge that implies a knowledge specifically about relationship between living beings and the environment that has emerged as a handed down, site-specific knowledge for cultural survival [4]. It could also be considered as representing the cultural spatial strategies in dealing with the environmental living context where the cultural values, habitual routine and preferences are embedded [5]. The traditional making of material is often embedded with cultural values that are often neglected in modern industry [6] yet they strongly reflect the embeddedness with the contexts. Since the indigenous knowledge is closely related to the ecological everyday practice, the traditional way of making things is worth studying as a part of the overall ecological system within particular context.

This paper attempts to look into the traditional brick making process as an integral part of the whole ecological system of the environment. The process may

\footnotetext{
* Corresponding author: paramita@eng.ui.ac.id
} 
utilize the ecological elements of the environment and at the same time give ecological impact to the environment. The process may also result in health impacts to the workers due to the process and the waste production. As a process with a significant environmental and health impact, it is important to unravel the interrelation among the ecological values within the ecological system of the traditional brick making process in order to promote sustainability and well-being of the environment.

The objective of the paper is to present a review of the body of research on traditional brick making processes in different places, in order to gather various ecological aspects that are involved in the whole process. This paper will also provide a brief overview of the traditional brick making process in Pedurungan Kidul, Central Java, and various ecological aspects that might be embedded within the process. This preliminary study will provide a further research agenda to extract various lessons learned from the process of traditional brick making as a way to sustain the ecological practice of architecture.

\section{Methods of study}

This study consists of two main parts. The first part is a literature review to discover the variety of ecological aspects that are embedded in the process of traditional brick making. The literature review is conducted based on a number of journal articles containing the research that address various aspects of traditional brick making processes in different countries, including Bangladesh, China, India, Indonesia, Malaysia, Nepal, Portugal, Thailand, and Turkey. The analysis was conducted by identifying the main ecological aspects that become the focus of the study of the process. The second part is a preliminary analysis focusing on the traditional brick making process in Pedurungan Kidul, Central Java Indonesia. The aim of this analysis is to identify the ecological aspects that are embedded in the environmental and cultural context, including those that may not be covered by the studies previously reviewed. This analysis was aimed at discovering unique aspects that might be attached to the traditional process that could contribute to the ecological value of the indigenous building material process.

\section{Ecological aspects of traditional brick making process}

The reviews of the studies on traditional brick making process in different countries reveal various findings that addressed different environmental and technological aspects. Many studies of the brick making focus on the particular aspects of the production such as firing, quality control, the use of organic materials, the use of stabilizers and the resources used in the process through the methods of Life Cycle Analysis or LCA [7, 8]. Most of the environmental impacts of brick making process is associated with air emission in its production stages [7, 9]. The firing process of clay brick incorporates a high amount of heat energy which mostly causes impact in the air emission and energy consumption. Some studies focus on the effect of the implementation of newer technology in the firing process such as the introduction of Hybrid Hoffman Kiln (HKK), Vertical Shaft Brick Kiln (VSBK) and other systems to reduce the energy consumption and air pollution [10-12]. The studies have shown the positive impacts of the newer kiln system to the environment compared to the traditional processes. However, studies also suggest that the transition to the new technology system for existing traditional brick making process has been difficult [12], perhaps because the scale used for the newer technology is more suitable for industrial scale with mechanized system.

Other studies examined other ways to reduce the environmental impacts in the firing process. One of the ways is to reduce the temperature and energy needed for firing the brick by using specific clays or by giving organic additives [12]. Studies on the uses of various additives are also linked with other ecological values of the bricks, such as incorporating waste from other industries to improve the performance of the bricks itself and to increase the thermal insulation. The uses of agricultural organic waste in clay bricks production such as straw ash, rice husk ash, sawdust, tobacco, grass and disposed leaves have been found to act as pore-forming agents that can lower thermal conductivity with several small alterations of the other physical properties [13-15]. The addition of organic compound in bricks generally affect the water absorption which may be a concern for the use of wall for outdoor wall construction $[16,17]$ and increase the amount of water needed before the moulding stage [14]. The addition of organic compound in the correct amount could provide positive outcomes of the brick performance such as increasing the dry strength which can reduce the defects during handling before firing process. Those studies also suggest that the introduction of pores in the compound may reduce the compressive strength of brick yet still fulfill the required standard for building construction.

The use of other additives from various industrial waste has also been studied in the same manner. It includes the use of inorganic waste such as marbles, glass, coal fly ashes [17-19] and organic wastes such as recycled paper processing kraft pulp production residues $[20,21]$. The addition of organic waste from paper industries generally generates similar impacts to the organic waste from agricultural industry due to similar organic and fibric nature. The addition of inorganic waste offers different performance of brick properties compared to the use of organic additives. While the use of organic additives tend to be associated with the increase of porosity and thermal resistance and the reduce of compression strength, the use of inorganic waste tend to be associated with the increase of the strength except for the use of marble powder. Particular properties of marbles introduce pores by the calcination reaction in high temperature which mimics the effect of the use of organic additives. In conclusion, several studies have shown the positive impacts of the use of additives, both organic and inorganic, to the brick properties with fairly minimum negative effects. The main intention of the use of waste additives is mainly to 
reduce the waste from other industries which at the same time also to give particular desirable properties to the brick qualities.

The use of residual additives from other industries by informal sectors such as traditional brick makers can improve the symbiotic relationship between them [22]. However, the implementation of the use of waste additives in the brick industry is still facing many problems. The cost of the implementation often outweighs its economic benefit [23]. The potential release of possible contaminants within the waste materials during firing process might create more harm to the environment [24]. The availability of water also becomes a concern for brick industry since water is needed to create a fine mixture before the moulding process. Some traditional brick industries are struggled to find sustainable water resources for their production [1]. While the use of organic additives are found to give positives outcomes to the brick properties, it also increases the water required in the mixture which might be not desirable in the areas with limited resource of water [14].

The huge amount of energy during the firing processes has motivated some research to consider the process of brick making without firing process as an alternative production $[8,24]$. The main challenge of producing unfired bricks lies on the physical properties that is still below par compared to the fired ones. The use of stabilizer might improve the strength of the bricks while also creating considerable impacts to the environment [8]. The implementation of unfired brick technology still seems difficult to realise. Firing seems to be relatively irreplaceable in the brick making process especially in traditional industry.

The above studies indicate that some environmental aspects in the brick making process are conflicting to one another. For example, the use of organic additives may improve the thermal resistance but also increase the water absorption and reduce the compression strength. The introduction of cleaner firing technology which offers positive economic and environmental impacts also faces many difficulties due to technological differences and acceptance by the local customs. These conflicting aspects suggest the need for further research that could address how to balance the aspects into a sustainable system. The studies also suggest that many ecological aspects related to the brick making process are often studied separately and therefore the understanding of the ecological aspects involved in the process as a whole system is difficult to grasp.

Another issue identified through the review of the studies is that the analytical approach, such as Life Cycle Analysis (LCA) and laboratory experiment of brick material properties, tend to rely on quantitative measures of the ecological aspects. Within the context of traditional material process, the quantitative measure may ignore some aspects related to the cultural complexity of the process. It is important to see how local society values their environment as embodied within their local wisdom, natural context and cultural inheritance. Those values might be the basis of their actions which might be difficult to measure by the use of quantitative figures only. Our inquiries therefore attempt to seek the underlying values behind the traditional brick making process in one particular area to capture the wholeness of the ecological system of the process. The following section attempts to describe the possible ecological aspects that are embedded in the brick making process in particular area in Indonesia.

\section{Ecological aspects of brick making process in Pedurungan Kidul}

\subsection{Overview of the traditional brick making process}

Pedurungan Kidul is one of the brick production centre located in Central Java, Indonesia. Bricks in Pedurungan Kidul are produced through traditional process using the raw ingredients from local site (Fig. 1). In particular, the type of brick in Pedurungan Kidul is a red brick with rice husk. Hence it is often called bata sekam - bata means brick; sekam means rice husk. The addition of rice husk is essential in the making of bricks in Pedurungan Kidul because the raw material of these bricks is the mud gathered from the river sedimentation that is less pliable than the regular clay. The brick making workshops in Pedurungan Kidul are located along the river. Therefore, the location of the raw material is very close to the workshop and every time it rains, the supply of the raw material is refilled because the river influx brings more sedimentation from time to time.

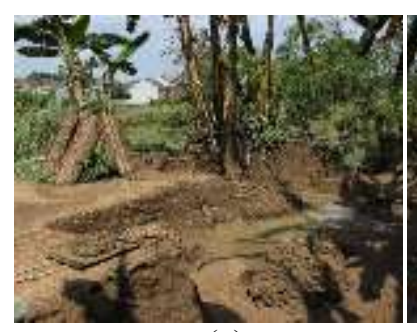

(a)

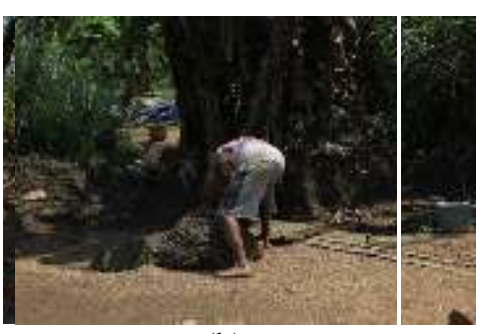

(b)
Fig. 1. The original location of the sedimentation mud as the raw material of bricks in Pedurungan Kidul

The traditional brick making process in Pedurungan Kidul is performed following the general stages of brick making that involve mixing, moulding, drying, and firing (Fig. 2). The sedimentation mud is mixed together with rice husk. Then, the mud and rice husk mixtures are moulded manually into brick pieces using a wooden cast. The process of mixing and moulding happens on the river bank area where the drying process also happens. All the moulded bricks are laid down on the ground and left to dried naturally by the sun for several days. After the raw bricks are dry and solid, the bricks are stacked on different places around the workshop, waiting to be fired. The firing process takes place in the traditional batch kiln located on the higher ground of the river bank. The kiln is constructed by the raw bricks that are stacked manually under a traditional structure. 


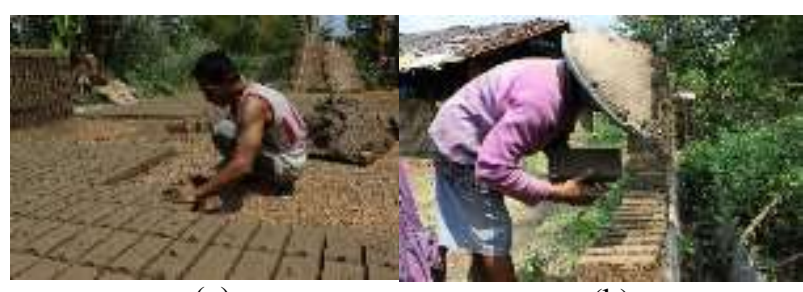

(a)

(b)

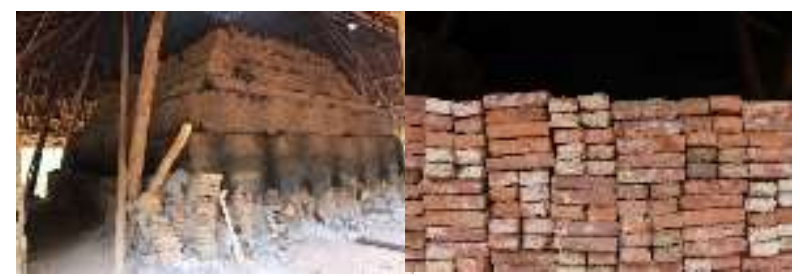

(c)

(d)

Fig. 2. Traditional brick making process in Pedurungan Kidul

\subsection{Ecological aspects in the traditional brick making process}

Within the traditional process of brick making in Pedurungan Kidul, some elements of ecology could be identified, comprising both environmental and culturalrelated elements. Some of the environmental related ecological elements are the origin of the raw material, the continuous availability of the raw material, the use of organic waste of rice husk to improve the quality of the bricks, and the construction of the kiln by the raw bricks themselves. These environmental related ecological elements are interfered with the cultural aspects as the whole process are based on traditional and local wisdom. These elements of ecology should be studied as a holistic part of ecological system where each of them are strongly interrelated with another.

The first element of ecology is the origin and availability of the raw material. Traditional brick making workshop in Pedurungan Kidul is located along the Banjir Kanal Timur River where the the raw material of sedimentation mud is originated. The making process takes place in the same area, just a few meters from the river bank, so there is no distribution and transportation needed. It saves cost for money, time, and energy. Beside, the sedimentation mud as the raw material in the making process is regularly refilled by the rain that cause the river influx to carry mud from the upstream. The use of the sedimentation mud from the river is a traditional way of making bricks that has been done for many years in Pedurungan Kidul as part of its indigenous knowledge.

The second element is the addition of natural waste of rice husk in the brick mixture. The brick craftsmen in Pedurungan Kidul consider the sedimentation mud from the river as a potential raw material for making bricks. However, in practice, mud is not as pliable as clay. Therefore, as part of their indigenous knowledge they add the organic waste of rice husk into the mud mixture in order to make more pliable mixture of brick. The addition of rice husk in the making process become an attempt to utilize the natural organic waste. At the same time, this addition produces the bricks with a very rough texture which, in the application, allows the cement to nicely fill the texture and grab the bricks very well.

The third element is the construction of the kiln. The firing process of the traditional bricks in Pedurungan Kidul use the traditional batch kiln constructed by traditionally stacking the raw bricks in particular pattern (Fig. 3). In the process of firing, thousands of bricks are stacked creating a kiln with several openings where the firewood as the main source of fire are inserted. The traditional stacking methods and the firing techniques could ensure that the bricks are heated evenly and all of the bricks has the same quality after firing. The inequality of brick quality sometimes occurs but it is a part of the trial and error practice of the traditional knowledge. The firing process is performed under a traditional structure of firing house that is constructed out of wood, bamboo, and straws from the local area. There are several firing house in one are of workshop that is used one at a time. After the bricks are done, they are usually left in the firing house, waiting to be distributed. The next firing batch will use another firing house available.

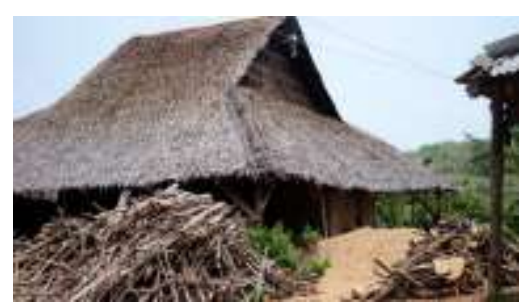

(a)

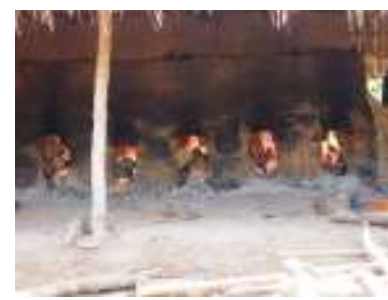

(b)

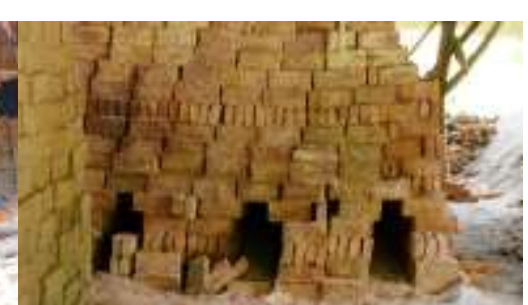

(c)
Fig. 3. Traditional batch kiln in Pedurungan Kidul constructed from the bricks

\subsection{Issues and further challenges of traditional material making process}

Those elements identified in the traditional brick making process in Pedurungan Kidul suggest the presence of ecological values that are embedded within the environmental and cultural context of the process. Some of the ecological elements have been previously addressed in many studies as already reviewed in the previous section. Nevertheless, there are some uniqueness of the aspects that may contribute to the discussion on the ecology of material making process.

Studies have found several issues in the firing process of the bricks due to energy consumption and air pollution [7, 9] and thus some alternative firing technology were proposed [10-12]. In the traditional brick making process in Pedurungan Kidul, the main 
feature of the traditional kiln is the utilization of the bricks themselves as the kiln. This means that the produced materials also become the means for the firing process. There is no data yet on the environmental impacts of the current firing technology, and thus more specific research to discover such impacts is necessary. However, it is also important to acknowledge the indigenous process that utilize the bricks as the kiln for firing the other bricks, which are then replaced by other bricks in the subsequent firing batch. This suggests a particular form of material recycling that should be taken into account when evaluating the impact of the traditional firing technology.

Other ecological aspects are related to the use of raw materials obtained locally and the addition of rice husks in the mixture of bricks in Pedurungan Kidul. These might have some effects on the performance of the bricks. Many studies have attempted to examine the physical properties and performance of bricks made with various kinds of organic additives [12-15]. The effects on physical properties and performance obtained by the addition of rice husk in the brick mixture with local mud in Pedurungan Kidul has not been studied systematically. Nevertheless, it is important to consider that the use of materials is not only about the physical properties or performance of the material product. The use of ingredients obtained from local site suggests the advantage of less transportation compared to brick making the industry that obtain the ingredients from elsewhere. The use of rice husks should also be considered as a part of larger ecosystem of farming community in the surrounding area. It reflects the interrelation between the brick making industry and farming activities that are both important for the economic development of the society.

The ecological values found in the traditional brick making process could be considered as a part of indigenous knowledge that become the basis for the practice of making in the built environment [2]. They demonstrate the site-specific knowledge in particular area that has been handed down across generation in particular culture [4] and become the common practice that has been sustained until the present. The traditional brick making process in Pedurungan Kidul illustrates how the material practice becomes a reflection of cultural and social practices of the community, and this is only one case among many others that may be further investigated in different traditional brick making processes in different contexts [6].

Understanding the ecological elements in the traditional brick making process requires the awareness of how each element is related to one another. Therefore, weighing the advantages and the disadvantages of the traditional process is not simple because various aspects of performance, environment and culture are often closely interrelated. Further study needs to consider thoroughly such interrelation among aspects and not just examining particular aspect independently.

This understanding is also critical when there are further attempts to introduce any new technology or methods of working to achieve better performance in terms of energy and physical properties of the bricks. As already suggested by previous study, the introduction of new technology is not always easy because often the new technology is not suitable for the scale of traditional industry [12]. The discussion on traditional making process of bricks in Pedurungan Kidul suggests that there are some indigenous, ecological aspects of the process, and they might not be easily replaced by other new technology or methods. The procedures and the techniques of the making that have been handed down across generation has formed the material practice that is strongly based on the traditional local wisdom. It becomes necessary to acknowledge the presence of these ecological elements that are attached strongly to the environmental and cultural context of material making.

\section{Conclusion}

The traditional brick making process has been practiced in many countries as a part of indigenous architectural production. The reviews of the studies on traditional brick making process indicate various ecological aspects that are involved in the process. These aspects include the materials, methods, technology, the impacts of the process toward the environment and health, as well as the quality and performance of the brick produced by the traditional process. Most studies tend to examine these aspects quantitatively and address each element separately. Nevertheless, it is important to consider these aspects as an integral part of a comprehensive ecological system and its contribution in sustaining the ecology.

The description of the traditional brick making process in Pedurungan Kidul suggests that many ecological elements might be present as a part of environmental and cultural context. This may require further research that addresses the ecological elements as a whole comprehensive system. Further research agenda may include the studies on the interrelationship among the elements involved in the traditional process through both quantitative and qualitative measures, in order to obtain comprehensive understanding of the system as a whole. The quantitative methods of examining the physical elements of the process need to be complemented by the more qualitative approach, including ethnographic study, to discover the social and cultural aspects that are relevant to the ecological elements of the process. By acknowledging the presence of such elements within the whole ecological system, it is possible to understand the values contributed by the traditional material process as a contextual ecological architectural practice in particular context of environment and culture.

This article's publication is supported by the United States Agency for International Development (USAID) through the Sustainable Higher Education Research Alliance (SHERA) Program for Universitas Indonesia's Scientific Modeling, Application, Research and Training for City-centered Innovation and Technology (SMART CITY) Project, Grant \#AID-497-A-1600004, Sub Grant \#IIE-00000078-UI-1. 


\section{References}

1. N. Kolodziejek and L.S. Tey, IJSTR, 18(1), 20-34 (2016)

2. P. Memmot and J. Davidson, TDSR, 19(20), 51-68 (2008)

3. A. Agrawal, DECH, 26(3), 413-439 (1995)

4. J.A. Drew, COBI, 19(4), 1286-1293 (2005)

5. Y.A. Yatmo and P. Atmodiwirjo, IJTECH, 4(1), 24$33(2013)$

6. M. Johanes and A.R. Wahid, In, 1(1), 79-86 (2018)

7. M.I. Almedia, A.C. Dias, L.M. Arroja and A.B. Dias, Portugal SB10-Sustainable Building Affordable to All (Vilamoura, Portugal, 2010)

8. M.E. Zachau Walker, Modeling environmental impact of unfired bricks in India ( $\mathrm{PhD}$ Thesis, Massachusetts Institute of Technology, 2013)

9. B.M. Skinder, A.Q. Sheikh, A.K. Pandit and B.A. Ganai, JENE, 6(1), 1-11 (2014)

10. S.K. Pariyar, T. Das and T. Ferdous, IJSTR, 2(5), 184-187 (2013)

11. M. Hossain and A.M. Abdullah, BUPJ, 1(1), 79-89 (2012)

12. C. Weyant, V. Athalye, S. Ragayan, U. Rajarathnam, D. Lalchandani, S. Maithel, E. Baum and T.C. Bond, EST, 48(11), 6477-6483 (2014)

13. D. Tonnayopas, P. Tekasakul and S. Jaritgnam, Technology and Innovation for Sustainable Development Conference (Khon Kaen University, 2008)

14. I. Demir, J. Wasman, 28(3), 622-627 (2008)

15. C.M. Chan, IJCESCAE, 5(1), 7-13 (2011)

16. A. Rachmawati and I.N. Saputro, ER, 11(1), 16-22 (2015)

17. S. Malik and B. Arora, IJIRCST, 3(4), 19-21 (2015)

18. N. Bilgin, H.A. Yeprem, S. Arsplan, A. Bilgin, E. Günay and M. Marşoglu, J. Conbuildmat, 29, 449457 (2012)

19. I. Demir, WMR, 27(6), 572-577 (2009)

20. M. Sutcu and S, Akkurt, J. Ceramint, 35(7), 26252631 (2009)

21. I. Demir, M.S. Baspinar and M. Orhan, J. Buildenv, 40(1), 1533-1537 (2005)

22. A. Bain, M. Shenoy, W. Ashton and M. Chertow, J. Resconrec, 54(12), 1278-1287 (2010)

23. M. Hodge, J. Ochsendorf and J. Fernández, J. Jclepro, 18(12), 1190-1199 (2010

24. L. Zhang, J. Conbuildmat, 47, 643-655 (2013) 